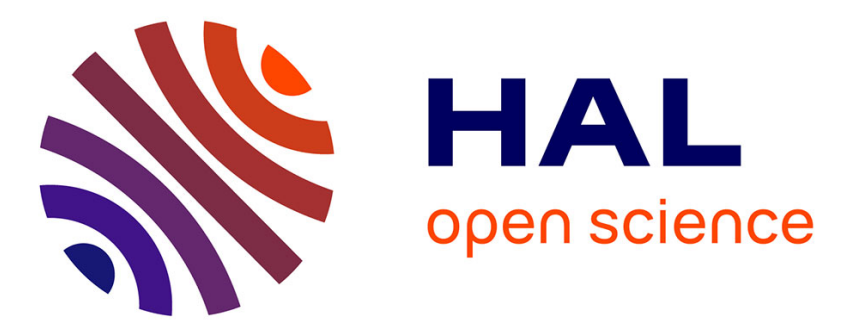

\title{
Determinants of Mobile Learning in Indigenous/Cultural Contexts: The Phenomenon in Canadian First Nations
}

Ben Akoh

\section{To cite this version:}

Ben Akoh. Determinants of Mobile Learning in Indigenous/Cultural Contexts: The Phenomenon in Canadian First Nations. 11th IFIP World Conference on Computers in Education (WCCE), Jul 2017, Dublin, Ireland. pp.24-34, 10.1007/978-3-319-74310-3_4 . hal-01762884

\section{HAL Id: hal-01762884 \\ https://hal.inria.fr/hal-01762884}

Submitted on 10 Apr 2018

HAL is a multi-disciplinary open access archive for the deposit and dissemination of scientific research documents, whether they are published or not. The documents may come from teaching and research institutions in France or abroad, or from public or private research centers.
L'archive ouverte pluridisciplinaire HAL, est destinée au dépôt et à la diffusion de documents scientifiques de niveau recherche, publiés ou non, émanant des établissements d'enseignement et de recherche français ou étrangers, des laboratoires publics ou privés.

\section{(c)(1)}

Distributed under a Creative Commons Attribution| 4.0 International License 


\title{
Determinants of Mobile Learning in Indigenous/Cultural Contexts: The Phenomenon in Canadian First Nations
}

\author{
Ben Akoh \\ Faculty of Education, University of Manitoba, Canada \\ umakoh@myumanitoba.ca
}

\begin{abstract}
This goal of this qualitative study was to identify the determinants that assist post-secondary indigenous learners in an isolated fly in-only community to adapt and orient themselves between Eurocentric and Indigenous ways of learning. Digital technology (specifically mobile devices) was used to produce documentation for their adaptation and orientation. The outcomes of the study produced determinants that informed learning with digital technology in the research context. Informants showed a deep understanding of the problem, they were well meaning, eager and responsive to the study. The problem was more complex and participant responses indicated that rethinking and restructuring of the goals and tentative solutions for successful learning were needed. The solutions cannot be simply more technology or more pedagogy. Future research is key, but those research efforts must enter the community with a truly open mind and without any pre-fixed solutions.
\end{abstract}

Keywords: digital technology, aboriginal, Manitoba, pedagogy, adult learning.

\section{Introduction}

This qualitative study was to identify the determinants that assist post-secondary indigenous learners in an isolated fly-in only community in Northern Manitoba to adapt and orient themselves between Indigenous and Eurocentric ways of learning. Digital technology, particularly mobile devices was used as a tool for producing documentation for how these learners adapted and oriented themselves. By understanding this negotiation and adaptation educators may be better positioned to understand key determinants for learning in indigenous communities. They may also be able to facilitate technology mediated programming at the post-secondary level, especially in contexts where multiple worldviews are at play.

The ethnographic study produced a framework which highlighted a set of determinants that could: a) guide policy makers, government agencies, school administrators, educators and students to better collaborate for negotiated learning and adaptations; b) support these stakeholders to recognize that adaptations and orientations between cultures are required for indigenous students to succeed, and c) cause them to explore the affordances of digital technology for adaptations and orientations.

Determinants as used in this study imply the presence of certain factors that produce expected outcomes that might have impact on a people and their community. The notion of determinants for societal benefit emanated from the public health 
sector. Irwin, Solar \& Vega noted that public health scientists in the 1940s observed that "social conditions decisively influence health" [10]. They further argued that "the sanitary campaigns of the nineteenth century and the work of the founders of modern public health reflected awareness of the relationship between people's social position, their living conditions, and their health outcomes" [10].

Since the 1940s there have been numerous agendas that tend to link other social determinants to health. The 1948 World Health Organization's constitution for instance had consistently linked agriculture, education and social welfare to social determinants of health. Research in examining the notion of determinants as an important concept in indigenous Canadian education is captured in studies by Mignone \& O’Neil [19] and by Mignone, Elias \& Hall [18].

Social capital as a determinant of health has both individual and ecological characteristics. Individual characteristics usually consist of education, income or gender. Ecological characteristics usually consist of the level of crime, level of pollution or the willingness for community members to help themselves. Access to information and knowledge that help individuals make important decisions about their health are also important determinants of health. Digital technology, especially its use for learning have also been known to play an important role as a determinant of health.

The study was conducted in a rural, fly-in, Indigenous First Nations community located $940 \mathrm{kms}$ North of Winnipeg, Manitoba, in Canada. This community was accessible only by plane and winter ice roads. The remoteness of this community and its information and communications technology challenges made it a most appropriate research context for this study. The study was designed to explore the main research question, "What are the determinants that assist post-secondary indigenous learners in a rural Manitoba community to adapt and orient between Eurocentric and Indigenous ways of learning?” Fourteen participants were involved in the ethnographic study.

Prior to colonization in the 1600s Indigenous people inhabited the land called Canada today. With the arrival of Europeans, they were colonized and their way of life was transformed. Their learning methods were undermined and they were stripped of their culture, land and identity. Terms such as systematic imperialism and "cultural genocide" have been used to describe these acts of colonization [4, 28]. The residential school system was a tool used to strip the indigenous person of their identity. Indigenous people were no longer in control of their own education.

In 2004, after several years of negotiations, a post-secondary institution that would meet the educational needs of indigenous learners in northern Manitoba was formed. The University College of the North was set up to undo some of the previous colonial wrongs and to provide "an inclusive range of credible, accessible and attainable postsecondary learning opportunities to indigenous and northern residents” [22]. It did this through its eleven community centres spread across the northern parts of the province of Manitoba. This study was conducted in one of the eleven centres. The study participants were also adult students enrolled in a post-secondary program at the center.

At the university, traditional elders played an important role in shaping its direction and governance. Information and communications technology was used to connect the two main campuses to the eleven regional centres. Schools in this community were known to historically register high attrition, low completion and participation rates. 


\section{Literature Review}

Over the years, technology, policy and international development proponents have tried to address the social consciousness gaps missing from the crazed and rushed implementations of technology for poverty alleviation projects in indigenous communities in developing countries. After several millions of dollars and pounds that resulted in little to no reforms, international financial institutions such as the World Bank and the IFC began asking serious but fundamental methodology questions: what went wrong, where, how, and why did these technology projects fail [12]?

Whereas some of these projects have somewhat contributed to improving certain economic, social, and cultural aspects of the indigenous beneficiaries, there have been unintended consequences from their implementations. Most of which led to largescale project failures. Beneficiaries completely lost faith and trust in the so-called technology for development and their implementers. Heeks [9] argued that only onefifth of technology projects in industrialized countries succeeded at the time. They were even far less numbers in indigenous communities in developing countries.

Educational technology requires more careful thought and planning than the quick brushstroke implementations of the past. Not many countries or groups can afford luxuries associated with trial and errors methods, especially indigenous First Nations communities in Northern Manitoba where resources are scarce, cultural and geographical factors pose challenges and where funding to public schools is tight. A balance ought to be struck between the often small available funding and "innovation" in technology projects especially in Canadian post secondary institutions.

In this regard, the application of digital technology for education should distance itself from conjectural brush-strokes implementations that assume little recognition of the contextual and cultural specificities of their target communities [16]. The most obvious of these assumptions is that the cognitive requirements for negotiation and adaption to technology and its use in indigenous contexts are not any different than those in other contexts. Technology implementations thereby result in the mismatch of policy, practice, and implementation between the context they were imported from and the one they were implemented.

But technology implementation can take on a different approach $[1,8,17]$. Approaches that negotiate between Indigenous methods and Eurocentric ones may be necessary. Such approaches see multiple cultures as different but equal. They are approaches that are founded on indigenous principles, cultural methods, social capital, and pedagogical strategies.

Indigenous learning in Canada is varied and specific to an individual's learning milieu. It is "place-based and includes a variety of knowledge sources...[such as], the land [which] is the ultimate source of knowledge" [21]. Indigenous learning "cannot be separated from the larger social and cultural matrix from which it is defined". It is a process, and not an event, "spanning the four stages of the life cycle - child, youth, adult and Elder"[17]. Indigenous learning is holistic, connecting with the learner at the intellectual, spiritual, emotional and physical levels.

It is difficult to understand indigenous learning perspectives using Eurocentric lens because "Indigenous knowledge does not fit the Eurocentric concept of culture, it is 
not a uniform concept among all Indigenous peoples; and it cannot be separated from its bearer or codified into a definition" [17]. It is for this reason that the study described in this paper focused on the indigenous aspects of the learner. Technology was used in the study as a tool for the documentation of negotiations between Indigenous and Eurocentric learning. The term "indigenous" is normally presented in lower case " $\mathrm{i}$ " but used in capital case "I" when it describes a noun or used along with the term "Eurocentric" in the same sentence.

This paper does not promise to promote digital technologies in an indigenous community under the guise of development $[29,30]$. Neither does it promise that digital technology could be the silver bullet for an emancipated indigenous educational community. Certainly, it does not intend to replicate the failed development practices of the past. It focuses rather on how indigenous learners negotiated learning and how they adapted between different worldviews. It then suggests how educators and researchers could frame pedagogy in an indigenous culture-centric manner that respects and responds to the core needs of the Indigenous learner.

\section{Study Design, Method/Methodology}

The ethnographic study involved fourteen research participants consisting of two participant groups. The primary group consisted of eight participants who lived in the research community, had completed high school, were enrolled in a post-secondary program, could communicate in English and consented to participating in the study. Primary participants were directly involved in the research activities. The secondary group consisted of six participants who were either elders in the community or had provided technical, academic or administrative knowledge or support directly to the research community. Secondary participants were not directly involved in the study's activities but provided contextual information. All participants were identified using purposeful sampling method [7, 27].

Purposeful sampling allows an investigator to sample and select "information-rich purposeful cases for study in depth...from which one can learn a great deal about issues of central importance to the purpose of the inquiry...Studying information-rich case yields insights and in-depth understanding rather than empirical generalizations" [24]. Ethics approval to conduct the research was granted by the University of Manitoba Education/Nursing Research Ethics Board, and the University College of the North's Research Ethics Board.

Primary research participants utilized native applications on standard mobile devices such as the camera, video and voice recorders to create cultural digital artifacts from culture-centric community activities. These included: a) participatory video (creating recordings of interviews with parents, family members, elders, community members, leaders; of community and farms/gardens); b) picture/photo voice (images were used to create stories about their communities, family history and heritage); c) personal connection story (participants created a paper map of their family tree, which they converted to digital form), and d) personal reflections (production of critical reflection of learning practices and journey through selfquestioning and assessment, used to create update blogs and to create personal video logs). 
These activities led to the production of digital artifacts that captured histories, family heritages, ancestry, and stories. Activities were conducted outside the classroom and within the community so that learning is consistent with indigenous pedagogy. By undertaking the activities outside the classroom, participants were able to recognize their own cultural and indigenous learning practices, and to use that as a base to connect with learning in the classroom.

A safe frame was essential for the study to be performed [20]. A safe frame is a set of principles, protocols, boundaries and understanding that gave participants agency, ownership, and control of the research activities and its products. The frame was defined by a series of policies and frameworks for conducting research in indigenous communities. They consists of the Ownership, Control, Access and Possession framework [23], the Tri-Council Policy Statement: Ethical Conduct for Research Involving Humans [5], and the Integrated Knowledge Translation framework [6]. Principles were created by the participants themselves through several years of extensive relationship and confidence building between the research community and the researcher.

Upon completion of the research activities, digital artifacts were created. They were brought back into the classroom and primary participants reflected on and analyzed them. To help with their analysis, participants responded to the question, "What resonated with you most while conducting the research activities?" As a phenomenological study, their response helped to respond to the overarching research question, "What are the determinants that assist post-secondary indigenous learners in a rural Manitoba community to adapt and orient between Eurocentric and Indigenous ways of learning?” Participants captured their reflection in blog posts, tweets, Wikipedia pages, and on notepads. By critically analyzing their activities, participants were able to:

a) Produce documentation that reflected learning from a "familiar" Indigenous base of their culture to an "unfamiliar" Eurocentric learning context.

b) Establish the requirements for understanding concepts in this new "unfamiliar" base in which they were expected to learn.

c) Build the necessary bridges to transition from the familiar indigenous cultural base to the unfamiliar Eurocentric cultural context.

d) Make the cognitive shift from one to the other.

Primary participants were then interviewed using the following questions: a) How valuable would educational technology, especially mobile technology contribute to your academic success and assurance the value of your learning? b) What individual stories emerge from your use of technology that you think contributes to or impedes your learning? c) What factors motivate your use of educational technology such as mobile technology? d) How could educational technology use improve engagement within your community?

Their responses formed the primary research data. They were recorded, anonymized, transcribed and checked for correctness.

Data analysis was performed to check for references to digital technologies such as mobiles devices, computers, electricity, cable infrastructure and the internet. It was also analyzed for references to culture, such as dances, story telling, communitybased occupations, i.e. fishing, trapping, ceremonies, family gatherings and heritages. Emergent themes were further analyzed for sub-themes. 
The Indirect Behavioural Measures method was used to identify cognitive movements from Indigenous learning to Eurocentric learning [25]. This method suggests that the researcher retrieves the required data based on inferences from participants' statements. This is different from directly interpreting their statements. Here, participants' attitude towards themselves could be inferred rather than as a measure of explicit behaviour. This approach is useful because some social cases may prevent research participants from speaking about themselves or providing data about their social behaviour. Sometimes participants may not be aware of the information required, may not have "insight into their behaviours", or may be tempted to "impression manage" the information they provide, thus affecting the quality of the data collected. Indirect Behavioural Methods "do not require an explicit response from participants, yet reveal reliable information about underlying cognitions” [25].

Upon analysis the study's findings produced broad themes in four areas:

a) The technical, community, and cultural disconnects resulting from the application of digital technology for learning.

b) The socio-cultural challenges associated with the implementation of digital technology for learning.

c) The unintended consequences of digital technology that had negative impacts on the community.

d) The affordances of digital technology for creating connections with content that enhanced learning.

\section{Findings and Discussion}

Digital technologies are a double-edge sword [14] capable of enabling or disrupting existing indigenous practices. Simply because they produced positive outcomes in other contexts did not mean they could produce the same outcome in the research context. Their use was therefore carefully scrutinized so that they did not disenfranchise the research participants. Determinants are italicized.

The technical, community and cultural disconnects resulting from either the positive and/or negative impacts of digital technology on the community determined how community members related with themselves and how the participants leveraged digital technology for their learning. Specifically, the absence of a robust internet infrastructure created a technological "disconnect" that prevented the introduction of value added services such as tele-health or more advanced forms of learning with digital technology. There had been past and renewed promises to build a northern wide fiber-optic infrastructure that would carry the traffic between northern indigenous communities and from these communities to the south and then on to the global network [11]. Such infrastructure would be able to address some of the present challenges of learning with digital technologies.

Connecting the local with the global is an important determinant for economic development [13]. The availability of a community-wide fiber infrastructure is an essential determinant for learners to access and create indigenous content, to transform from knowledge consumers to knowledge creators and to enable cognitive movements from one worldview to another to occur. However, the presence of a network alone is insufficient to deliver these sorts of value. More would have to be 
done to leverage the existence of digital technology for instance, for economic, social and cultural gains.

The presence of a collaborative platform that could leverage inherent indigenous traditions of orality, collaboration and dialogue for solving problems and for developing the community is another important determinant. A collaborative platform could be extended to include all stakeholders that should have interest in the learning goals of the indigenous community. Having the local government administration, provincial and federal government departments and the communities themselves become involved in dialogue for strengthening community development could be a significant determinant for sustainable service delivery in indigenous communities. Value added services like tele-health and education could benefit from such platforms. If they exist, they should be strengthened so that better dialogue, collaboration and cooperation continues. If none exist, one should be created.

With respect to the value of such platform for Indigenous education, community members like parents should be invited to participate in the learning of their children. Specifically, they should be involved in indigenous learning methods as a base for which other methods of learning including Eurocentric forms could be scaffolded.

The second thematic outcome focused on the socio-cultural challenges of digital technology implementation and its use for learning within the community. This outcome related to the confidence that community members had on digital technology's affordance. It also related to its affordance for fostering cognitive movements between worldviews.

Participants, who through some form of indigenous culture-based reasoning were able to reflect on and to describe their skepticism of digital technology, were also able to reflect on digital technology's positive impact on their learning. They were able to decide whether or not it had an affordance to facilitate cognitive movement from one cultural space to another. To necessitate its use, the presence of a safe frame was significant. This frame ensured that some level of privacy of individual data and equity between cultures at play in the context and between actors involved in their learning should be present.

Another important sociocultural challenge to learning concerned the presence of trauma in the community. Trauma affected learning, and more so learning with digital technology. As a result, those who wanted to explore movements between cultures might have used digital technology created in one culture to implement learning in another culture without paying attention to its potential to produce harm. This kind of digital technology use seemed to produce trauma in the indigenous community instead of positive affordances. It further hampered cognitive movements especially when learners feelings and emotions where not considered during the use of such technologies. Community members suffered various forms of traumatic experiences. In spite of these, they showed courage, resilience and they exhibited willingness to continue to learn. Even though trauma had resulted in the frequent deaths of community members, some by suicide, current traumatic circumstances reminded participants of the impact of past practices such as the residential school system, the role of such schools, and the lasting impressions they had made on them, their parents and grandparents.

Those who design and facilitate learning in indigenous communities should remember that digital technology might be alien to the context of implementation. 
And as a result, could produce outcomes that may not be suitable to that context. They should also consider existing pedagogical strategies so that their learning methods holistically involves a recognition of the learners' history and includes consideration for their Indigenous culture as the base on which learning can be scaffolded and on which successful educational strategies can be developed. From this foundational base links to Eurocentric learning methods could be established. These are essential determinants for learning to take place in indigenous communities.

The third outcome was concerned with the unintended consequences of educational technologies in the community. Individual and community related "connects" were established between digital technology and community members. Most of these connects were predicated on the recent upgrade of the local mobile infrastructure in the research community. Some unintended outcomes resulted from the use of digital technology and this upgrade. They seemed to enhance an existing undesirable bullying behaviour, by extending it to the online space. Cyberbullying emerged as a negative consequence of digital technology use in the community.

Even though it might be difficult to determine potential negative consequences of digital technology implementation such as cyberbullying, McLuhanistic methods for eliciting the impacts of digital technology [15] or the systemic order effects method [26] could enable educators to proactively elicit some unintended negative consequences and to prevent them before they happen. Cyberbullying should not be tolerated in any community, especially in an indigenous learning context where suicide is rife.

As a double-edged sword, digital technology produced affordances that were somewhat positive and that could have positive impacts on learning in the research community. Besides producing more community-based training and awareness programs that leverage digital technology, pedagogical strategies that highlighted digital technology's positive affordances seemed to help shift learners' focus from the simpler social benefits of digital technology use to more profound uses. Digital technology seemed to help learners to transition from simply storytelling to storywork [2, 3]. Storywork are more advanced ways of using stories for learning. Learners explored digital technology's affordance to remember culture, to keep and maintain records and archives of community cultures and practices. This retentive capacity of digital technology was useful for knowledge production and seemed to help community members to shift from consumers to producers of content.

The inherent ability of technology to create unsafe environments was contrasted with its ability as a tool for safety; one that could help learners communicate and interact safely and to safely share information, within the context of a safe frame. Its application here was done in a way that recognized, enhanced and did not undermine cultural practices for communication and interaction.

\section{Conclusion}

Digital technology was used as a tool to produce documents for learning in an indigenous context where learners were expected to learn and succeed using Eurocentric methods. Historically, learners in this context have been known to not succeed or drop out of school. Success here was often defined from a Eurocentric perspective. The Eurocentric methods of learning that have been associated with 
colonizing activities of the past have not helped. Even though recent approaches have led to the inclusion of indigenous methods of learning in post-secondary education, there are still challenges in learners' understanding of expectations for success.

This study has shown that certain determinants are essential for learners to succeed in this context. Indigenous learners have shown that they would like to "feel good" about their learning. They have also indicated that they would like learning to take place in the confines of a safe frame, which is constructed on policies and frameworks that respect them and their tradition. They should be allowed as participants in the construction of this frame. They should be able to define the standards for equity and privacy between their culture and that of their educators. They should ultimately develop sufficient confidence in their educators for learning to the successful.

Within the confines of a safe frame, participants who felt good about their learning were more likely to engage, share and connect with others and to learn. Within this context, they were also able to create "new things", to innovate and to undertake learning that were previously not possible. Educators and learners should use digital technology to connect the past with the present, and to connect the present with the future such that it could help indigenous learners to become more grounded in their culture. This grounding is essential as a scaffold for learning to take place in a foreign cultural context, i.e. Eurocentric contexts in which they are expected to succeed. In the face of current migratory patterns in which learners from other global contexts are introduced into and expected to succeed in Eurocentric learning contexts, the aforementioned determinants may be useful considerations.

More work is required to explicitly define the determinants for learning to take place in indigenous communities. For instance, future research should explore the extent to which each determinant should be present for learners to succeed.

Acknowledgments. I am pleased to acknowledge the generous financial support of the Social Science and Humanities Research Council of Canada through the Manitoba Research Alliance grant: Partnering for Change - Community-based solutions to Aboriginal and inner-city poverty. I also appreciate my "community champion”, and my doctoral advisory committee.

\section{References}

1. Aikenhead, G.S.: Toward a First Nations Cross-Cultural Science and Technology Curriculum. Sci. Educ. 81, 2, 217-238 (1997).

2. Archibald, J.: Indigenous Storywork: Educating the heart, mind, body, and spirit. UBC Press, Vancouver (2008).

3. Atleo, M.R.: Understanding Aboriginal Learning Ideology Through Storywork with Elders. Alberta J. Educ. Res. 55, 4, 453-467 (2009).

4. Battiste, M.: Indigenous knowledge: foundations for first nations. Indig. Nations High. Educ. Consort. 12 (2005)

5. CIHR: Guide to Knowledge Translation Planning at CIHR: Integrated and End-of-Grant Approaches. (2012).

6. CIHR: Integrated Knowledge Translation at CIHR: An Update. Particip. Res. @ Lunch. (2011).

7. Coyne, I.T.: Sampling in qualitative research. Purposeful and theoretical sampling; merging or clear boundaries? J. Adv. Nurs. 26, 3, 623-630 (1997). 
8. Ezeife, A.N.: Using the environment in mathematics and science teaching: An African and Aboriginal perspective. Int. Rev. Educ. 49, 3-4, 319-342 (2003).

9. Heeks, R.: Information Systems and Developing Countries: Failure, Success, and Local Improvisations. Inf. Soc. 18, 2, 101-112 (2002).

10. Irwin, A. et al.: Social determinants of health, the united nations commission of. Int. Encycl. Public Heal. 1, 64-69 (2008).

11. Jillian Taylor: Indigenous company to bring high-speed internet to all of Manitoba's First Nations communities - Manitoba - CBC News,

http:/www.cbc.ca/news/canada/manitoba/manitoba-first-nations-technology-council-highspeed-internet-1.3699650.

12. Laouris, Y., Laouri, R.: Can information and mobile technologies serve to close the economic, educational, digital, and social gaps and accelerate development? World Futures. 64, March 2013, 254-275 (2008).

13. Mata, F.J., Pont, A.: ICT for Promoting Human Development and Protecting the Environment. In: Mata, F.J. and Pont, A. (eds.) IFIP Advances in Information and Communication Technology. pp. 1-245 (2016).

14. McGrail, E.: "It's a double-edged sword, this technology business": Secondary English teachers' perspectives on a schoolwide laptop technology initiative. Teach. Coll. Rec. 108, 6, 1055-1079 (2006).

15. McLuhan, M.: Understanding Media: The extensions of Man. MIT Press, Cambridge, Massachusettes; London, England (1994).

16. McMahon, R. et al.: Putting the "last mile” first: Re-framing broadband development in First Nations and Inuit communities. (2010).

17. Michell, H. et al.: Learning Indigenous Science from Place. (2008).

18. Mignone, J. et al.: Validation of a Culturally Appropriate Social Capital Framework to Explore Health Conditions in Canadian First Nations Communities. Int. Indig. Policy J. 2, 1, 1-19 (2011).

19. Mignone, J., O’Neil, J.: Social capital and youth suicide risk factors in First Nations communities. Can. J. Public Heal. 96, SUPPL. 1, S51-S54 (2005).

20. Miller, M.: Creating a Safe Frame for Learning. J. Teach. Soc. Work. 21, 3-4, 159-176 (2001).

21. Mitchell, H.: School Science From the Eyes of the Woodlands Cree : Using the Migawap ... Can. Journals Nativ. Stud. 32, 2, (2012).

22. MKO: University College of the North: A Vision for Our Future. , Manitoba (2000).

23. OCAP/FNIGC: The First Nations Principles of OCAP, http://fnigc.ca/ocap.html.

24. Patton, M.Q.: Purposeful sampling. Qual. Eval. Res. methods. 2, 169-186 (1990).

25. Snowden, R.J. et al.: Indirect behavioral measures of cognition among sexual offenders. J. Sex Res. 48, 2-3, 192-217 (2011).

26. Souter, D. et al.: ICTs, the Internet and Sustainable Development: Towards a new paradigm. Int. Inst. Sustain. Dev. 39 (2010).

27. Suri, H.: Purposeful Sampling in Qualitative Research Synthesis. Qual. Res. J. 11, 2, 63-75 (2011).

28. TRC: Honouring the Truth, Reconciling for the Future: Summary of the Final Report of the Truth and Reconciliation Commission of Canada. Truth and Reconciliation Commission of Canada (2015).

29. Westhead, J.: Evans, Farm near Lake Naivasha, Kenya | Mobile for Development, http://www.gsma.com/mobilefordevelopment/evans.

30. Westhead, J.: Jaipal, Remote Rural Community, India | Mobile for Development, http://www.gsma.com/mobilefordevelopment/jaipal. 